\title{
Salvage SBRT for Previously Irradiated Lung Cancer
}

\author{
Steven K. Seung ${ }^{1,2^{*}}$, Matthew Solhjem ${ }^{1}$ \\ ${ }^{1}$ The Oregon Clinic, Portland, USA; ${ }^{2}$ The Earle A. Chiles Research Institute, Portland, USA. \\ Email: Steven.seung@providence.org
}

Received April 23 ${ }^{\text {rd }}, 2011$; revised May 24 ${ }^{\text {th }}, 2011$; accepted May 31 ${ }^{\text {st }}, 2011$.

\begin{abstract}
Purpose: Patients with locally recurrent lung cancer after definitive radiation therapy pose a challenge in management. Surgery is often not an option and chemotherapy offers poor long-term local control. Stereotactic body radiotherapy (SBRT) was investigated in an attempt to salvage locally recurrent lung cancer. Materials and Methods: From March, 2009 to January, 2010, 8 patients who had previous definitive radiation therapy for lung cancer at least six months prior to the diagnosis of locally recurrent disease underwent SBRT. Local recurrence was documented by CT, PET, and/or biopsy. Patients had to have Karnofsky Performance Score (KPS) > 70, no distant metastases by CT/PET and brain MRI, and lesions amenable to SBRT. SBRT dose deliveries were 12 Gy $\times 4,10 \mathrm{~Gy} \times 5$, 8 Gy x 5, or 20 Gy $x 3$ at the treating physician's discretion. No adjuvant chemotherapy was delivered. Results: Eight patients were included in this study. Patient characteristics were: 6 females and 2 males; ages 50 - 85 (median 71); KPS 70 - 100 (median 80); previous stage I (T1/2 N0) in 4 and stage II/III (T1/2 N1/N2) in 3, 1 pt had limited stage small cell; previous radiation doses 50 - 68 Gy in 1.8/2.5 Gy fractions; time interval from previous RT to SBRT 8 - 57 months (median 36 months); target lesion diameters $1.2-7.3 \mathrm{~cm}$ (median $4.5 \mathrm{~cm}$ ). With a median FU of 18 months (11 - 20 months), 7 patients are alive. Crude local/regional control to date is $86 \%$ with distant metastases in $1 / 7$ surviving patients. Acute pulmonary toxicities: cough grade 0 7/8, grade 1 1/8; pain grade 0 6/8, grade 1 2/8; dyspnea grade 2 8/8. 1 patient died 12 months after SBRT due to complications from a hip fracture. Her disease was locally controlled at the time of death. Discussion: In carefully selected patients who recur locally after previous conventional radiation therapy for lung cancer, SBRT can offer a well tolerated salvage therapy. Further follow up is needed to assess long-term local control, survival and toxicities.
\end{abstract}

Keywords: SBRT, Lung Cancer, Re-Irradiation

\section{Introduction}

Conventional radiotherapy yields local control rates in the range from $40 \%$ to $70 \%$ and 5-year survival in the range from $10 \%$ to $30 \%$. [1-3] In addition, conventional radiotherapy is performed via a protracted treatment course, typically six weeks, which consumes the precious commodity of time remaining for the patients. When these patients recur within the radiation field as the only site if disease, the standard of care has been to offer salvage chemotherapy or supportive care, as surgery is often a poor option. However, second-line chemotherapy does not produce durable responses. [4] Re-irradiation with conventional radiation has been reported as well with variable success. [5-9]

Stereotactic radiosurgery (SRS) and fractionated stereotactic radiotherapy (SRT) have become routine treat- ment options for patients with brain metastases. [10-15] High fractional dose is more effective for radiation resistant cells. This is suggested by the good local control seen in hypofractionated radiation therapy for nodal metastases and radiosurgery for brain metastases in melanoma. [16-18] However, the risk of long-term normal tissue complication is correlated with the fraction size. The tight conformality (and thus the avoidance of normal tissue) possible with radiosurgical techniques permits safer delivery of single doses in the range of 15 - $20 \mathrm{~Gy}$. Using prototypes for image-guided radiation therapy (IGRT) [19], stereotactic body radiotherapy (SBRT) which mimics SRT for extracranial disease, e.g., small sized lung cancers, has been reported where hypofractionated therapy in fractional doses of 12 - 20 Gy appeared to be relatively safe and effective resulting in local control rates of $80 \%-90 \%$ [20]. 
The translation of SRS and SRT to extracranial sites was limited by two problems. First, tumors in the body are subject to motion related to natural physiological process like breathing and digestion. Second, because the treatments are highly focused, image guidance needed to be such that the selected patients are properly treated with limited fields and that the target extent can be determined accurately. By the early 1990s, technological advances in both tumor motion tracking and image guidance allowed the concepts of SRS and SRT to be extended to extracranial sites where it is now known as SBRT. The American College of Radiology and the American Society of Therapeutic Radiology and Oncology have published guidelines that define SBRT and its proper conduct. [21] Patients selected for SBRT should have a limited number of demarcated tumors whose extent can be identified directly on treatment-planning image platforms or reliably fused by image registration techniques. Some method of tumor motion control must be used to avoid large margin treatments.

SBRT is an ablative therapy, and it should be understood that targeted tissue is likely to be destroyed. Many beams are brought in from multiple directions so that entrance dose is spread out. Beams are shaped to achieve conformality and rapid dose fall-off. The SBRT dosimetry approach is borrowed from intracranial SRS in which treatments have been well tolerated with long term follow-up. [22]

SBRT for lung tumors has been promising. [23-26] Onishi et al. reported overall local control rate of 92\% for patients who received SBRT with a biologic equivalent dose (BED) greater than $100 \mathrm{~Gy}$ and $74 \%$ for those with a BED less than 100 Gy. [27] Among those who were medically operable but instead underwent SBRT, the 3-year overall survival rate was $88 \%$ if the patients received a BED greater than $100 \mathrm{~Gy}$.

Based on these encouraging data demonstrating excellent local control and a relatively low risk of acute and late side effects, we treated patients who recurred locally after previous definitive conventional radiation therapy using SBRT alone. The primary endpoints were to assess local control and acute toxicities, and the secondary endpoints were to determine survival, late toxicities and distant metastases.

\section{Patients and Methods}

Eligibility criteria included tumors $\leq 7.0 \mathrm{~cm}$ at the time of evaluation for recurrence, time interval from previous radiation to recurrence $\geq 6$ months, age older than 18 years, Karnofsky performance status $\geq 70$, histologic or radiographic confirmation of active malignancy by fluorodeoxyglucose (FDG) positron emission tomography (PET), and absence of metastatic disease by chest com- puted tomography (CT)/PET and brain MRI. Previous diagnosis of limited stage small cell lung cancer was allowed. All patients were evaluated by a multidisciplinary team (thoracic surgery, radiation oncology, and medical oncology) and informed consent was obtained before treatment.

Four-dimensional CT scan was performed with the patient in the treatment position immobilized with the BodyFIX $^{\circledR}$ (Elekta, Atlanta, GA). The internal tumor volume (ITV) was delineated on the lung window of the planning CT scan. A 3 - $5 \mathrm{~mm}$ planning target volume (PTV) margin was used to account for intrafraction tumor motion. A radiosurgical intensity modulated radiation therapy treatment plan with $6 \mathrm{MV}$ photons was generated using Pinnacle v.9.0 software (Philips Medical Systems, Andover, MA) based on tumor location and geometry. Treatment was delivered on the Synergy $S \circledR$ (Elekta, Atlanta, GA) with the target localized with cone beam CT (CBCT) prior to each treatment delivery. The dose prescription was at the discretion of the treating physician; however, $90 \%$ of the PTV had to be covered by $99 \%$ of the prescribed dose. The normal tissue constraints in this situation are unknown. We therefore elected to follow the normal tissue constraint guidelines for RTOG 0813 (phase I/II study for SBRT for early stage, centrally located, nonsmall cell lung cancer, (http://www.rtog.org/members/protocols/0813/0813.pdf) understanding the uncertainties of valid applicability given our differing dosing patterns and the patients' previous radiation treatments.

Adujuvant chemotherapy was not given as the role of chemotherapy after salvage SBRT for locally recurrent non-small cell lung cancer is undefined. As for the patient with locally recurrent small cell lung cancer, since the only measurable disease was treated with SBRT, chemotherapy was not given until disease progression was documented. Patients were followed post SBRT with an initial repeat CT scan at two months, then repeat CT scans every 3 months. PET scan was repeated if indicated clinically and radiographically to confirm recurrence.

\section{Results}

\subsection{Patient Characteristics}

From March, 2009 to January, 2010, 8 patients who had previous definitive radiation therapy for stage I-III non-small cell or limited stage small cell lung cancer at least six months prior to the diagnosis of locally recurrent disease were evaluated for this study. Local recurrence was documented by PET and/or biopsy. SBRT dose deliveries were $12 \mathrm{~Gy} \times 4,10 \mathrm{~Gy} \times 5$, $8 \mathrm{~Gy} \times 5$, or $20 \mathrm{~Gy} \times$ 3 at the treating physician's discretion. No adjuvant chemotherapy was delivered. 
Patient characteristics were: 6 females and 2 males; ages 50 - 85 (median 71); KPS 70 - 100 (median 80); previous stage I (T1/2 N0) in 4 and stage II/III (T1/2 $\mathrm{N} 1 / \mathrm{N} 2)$ in 3, 1 pt had limited stage small cell; previous radiation doses 50 - 68 Gy in 1.8/2.5 Gy fractions; time interval from previous RT to SBRT 8 - 57 months (median 36 months); target lesion diameters $1.2-7.3 \mathrm{~cm}$ (median $4.5 \mathrm{~cm}$ ).

\subsection{Treatment Outcomes}

With a median follow-up (FU) of 18 months (11-20 months), 7 patients are alive. Local/regional control to date is $6 / 7$ (86\%) with distant metastases in $1 / 7$ surviving patients. An example of a patient's response is shown in Figure 1. The patient with the history of limited stage small cell who received 8 Gy $\times 5$ (BED 70) recurred locally at 11 months as confirmed by a repeat PET scan. This patient went on to receive second-line chemotherapy. To date, the sole distant metastasis was seen in the contra-lateral lung at 12 months from SBRT in patient 3 (Table 1). Due to the small patient numbers, only the crude survival data are shown in Table 1.

Acute pulmonary toxicities (common toxicity criteria [CTC ] v. 4) were relatively mild (Table 2). Seven out of
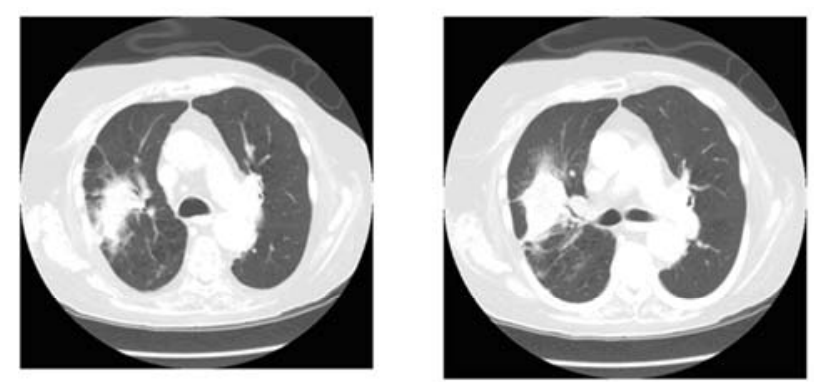

Feb 2009
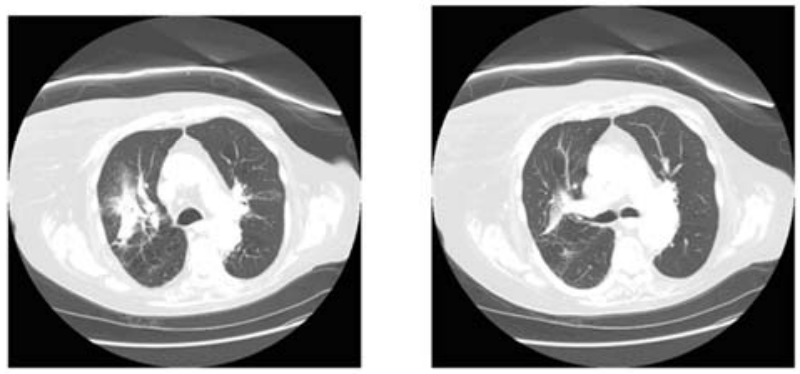

April 2011

Figure 1. 85 year old female (patient 2) with right lung cancer treated with initial radiation in March, 2006, with recurrence. Status post SBRT March 2009.

Table 1. Patient characteristics.

\begin{tabular}{|c|c|c|c|c|c|c|c|c|c|}
\hline Pt. No. & Age & Sex & KPS & $\begin{array}{l}\text { Prev } \\
\text { stage }\end{array}$ & $\begin{array}{l}\text { Prev RT dose } \\
\text { (Total Gy/fx Gy) }\end{array}$ & $\begin{array}{l}\text { Interval prev RT } \\
\text { to SBRT (mos) }\end{array}$ & Location in lung & Lesion dia (cm) & $\begin{array}{l}\text { SBRT dose } \\
\text { (Gy) }\end{array}$ \\
\hline 1 & 78 & $\mathrm{~F}$ & 90 & T1N0 & $68 / 2$ & 48 & LLL & 2.1 & $12 \times 4$ \\
\hline 2 & 85 & $\mathrm{~F}$ & 70 & T1N0 & $55 / 2.5$ & 36 & RUL & 7.3 & $12 \times 4$ \\
\hline 3 & 65 & M & 80 & T2N0 & $68 / 2$ & 37 & RLL & 6.3 & $10 \times 5$ \\
\hline 4 & 60 & M & 70 & T2N1 & $63 / 1.8$ & 57 & RUL & 4.5 & $10 \times 5$ \\
\hline 5 & 74 & $\mathrm{~F}$ & 100 & T1N0 & $66 / 2$ & 24 & LUL & 1.2 & $20 \times 3$ \\
\hline 6 & 81 & $\mathrm{~F}$ & 80 & T2N1 & $60 / 2.5$ & 15 & RUL & 5.1 & $10 \times 5$ \\
\hline 7 & 50 & $\mathrm{~F}$ & 100 & T2N2 & $60 / 2$ & 8 & RUL & 2.7 & $8 \times 5$ \\
\hline 8 & 68 & $\mathrm{~F}$ & 90 & $\begin{array}{l}\text { Limited } \\
\text { small cell }\end{array}$ & $50 / 2$ & 38 & RLL & 4.6 & $8 \times 5$ \\
\hline
\end{tabular}

Table 2. Patient outcomes.

\begin{tabular}{|c|c|c|c|c|c|c|c|}
\hline Pt. No. & $\begin{array}{l}\text { FU } \\
(\text { mos) }\end{array}$ & LC & Alive & $\begin{array}{l}\text { Cause of } \\
\text { death }\end{array}$ & $\begin{array}{l}\text { Regional/ } \\
\text { Distant } \\
\text { recurrence }\end{array}$ & $\begin{array}{l}\text { Acute side effects } \\
\text { < grade } 3\end{array}$ & $\begin{array}{l}\text { Late effects } \\
<\text { grade } 2\end{array}$ \\
\hline 1 & 20 & $\mathrm{Y}$ & $\mathrm{Y}$ & N/A & $\mathrm{N}$ & Mild SOB & Cough, SOB \\
\hline 2 & 20 & $\mathrm{Y}$ & $\mathrm{Y}$ & N/A & $\mathrm{N}$ & Mild SOB & SOB \\
\hline 3 & 18 & $\mathrm{Y}$ & $\mathrm{Y}$ & N/A & $\begin{array}{l}\text { Y at } 12 \text { mos in contra } \\
\text { lateral lung }\end{array}$ & Mild SOB & Cough, back pain \\
\hline 4 & 19 & $\mathrm{Y}$ & $\mathrm{Y}$ & N/A & $\mathrm{N}$ & $\begin{array}{l}\text { Mild SOB, } \\
\text { Mild dysphagia, Rash }\end{array}$ & SOB \\
\hline 5 & 18 & $\mathrm{Y}$ & $\mathrm{Y}$ & N/A & $\mathrm{N}$ & $\begin{array}{l}\text { Mild SOB, } \\
\text { Chest pains }\end{array}$ & SOB \\
\hline 6 & 14 & $\mathrm{Y}$ & $\mathrm{N}$ & Complications from hip fx & $\mathrm{N}$ & $\begin{array}{l}\text { Mild SOB, } \\
\text { Fatigue }\end{array}$ & SOB \\
\hline 7 & 13 & $\mathrm{Y}$ & $\mathrm{Y}$ & N/A & $\mathrm{N}$ & $\begin{array}{l}\text { Mild SOB, } \\
\text { Tachycardia }\end{array}$ & SOB \\
\hline 8 & 11 & $\mathrm{~N}$ at $11 \mathrm{mos}$ & $\mathrm{Y}$ & N/A & $\mathrm{N}$ & Mild SOB & SOB \\
\hline
\end{tabular}


8 patients had grade 0 cough, 1/8 had grade 2 cough. Two out of 8 had grade 2 pain while the rest denied any significant pain. All 8/8 described grade 2 dyspnea. 1 patient died 12 months after SBRT due to complications from a hip fracture. Her disease was locally and distantly controlled at the time of death.

\section{Discussion}

Re-irradiation for local recurrences of lung cancer has been reported using conventional radiation. Okamoto et al. reported 34 patients retreated (18 for "cure", 16 for palliation) with a median of $50 \mathrm{~Gy}$ (10 - 70 Gy in 1.8 3.0 Gy/fx).[7] The median survival after radical treatment was 15 months ( 3 - 58 months). Initially, 6 patients attained complete response (CR) and 8 patients partial response (PR). Long-term local control was not reported. Nineteen patients experienced grade $2 / 3$ pneumonitis, and 9 patients experienced grade $2 / 3$ esophagitis. Tada $e t$ al. reported 19 patients retreated after previous definitive radiation for stage III patients.[6] Eighteen patients were prescribed $50 \mathrm{~Gy}$ in 25 fractions and one patient was prescribed $60 \mathrm{~Gy}$ in 30 fractions. Five patients could not receive the prescribed dose due to acute complications. Median survival was 7.1 months with one and two year survival rates of $26 \%$ and $11 \%$, respectively. Patients with ECOG PS 0 - 1 had the best median survival of 12.6 months.

Our study represents preliminary results of evaluating the efficacy and toxicity of SBRT in patients who locally recurred after previous definitive radiation therapy. The main rationale for using SBRT was for its ability to yield excellent local control and relative low toxicities. With hypofractionated SBRT as performed in this study, we observed no treatment related deaths. Le et al. included 6 patients (out of 32) who had prior radiation therapy and recurred locally in a phase I dose-escalation study using single-fraction SBRT for lung tumors.[28] They observed two factors that appeared to be associated with treatment-related toxicity: a history of prior thoracic radiotherapy and chemotherapy use, either before or after SBRT. In terms of radiotherapy, they found that the 25-Gy dose in a single fraction resulted in significant toxicity in patients who had received prior thoracic radiotherapy. Two of their presumed treatment-related deaths were in such patients. The other factor that appeared to be associated with increased treatment-related toxicity was the use of prior or post treatment chemotherapy. In our study, the patients were treated with a variety of hypofractionation schemes, rather than a single dose, depending on the tumor size and location, and none received chemotherapy during or after SBRT. Chemotherapy was not given upfront since adjuvant chemotherapy after re-irradiation of a solitary recurrence is not defined. In addition, there were no additional lesions to follow to see the effects of chemotherapy. Chemotherapy, however, was offered to the one patient who developed multiple bilateral lung metastases 15 months after his SBRT salvage.

Recently Kelly et al. reported the M.D. Anderson experience of SBRT for patients with lung cancer previously undergoing thoracic radiation.[29] In this study, 11 out of 36 patients had in-field local recurrence prior to SBRT as in our study. Their patients received 40 or 50 Gy in four fractions. They had three patients with local failure within the SBRT PTV (22/36 pts had intrathoracic failures, most outside SBRT PTV volume) but did not specify if these recurrences were in the 11 patients with previous in-field recurrences. The three failures within the SBRT PTV's were attributed to compromised tumor coverage (only $22 \%$ - $24 \%$ of CTV receiving prescribed dose) or to suboptimal dose (40 Gy in 4 fractions).

In our study, all patients had $>90 \%$ of the PTV covered with a fractionation scheme resulting in BED of $\geq$ 100 with the exception on one patient who received $8 \mathrm{~Gy}$ x 5 (BED 70). This last patient who had a history of limited stage small cell lung cancer, recurred locally at 11 months as confirmed by a repeat PET scan. Interestingly, this site remained the only site of PET avidity.

\section{Conclusions}

This study suggests that in carefully selected patients who have local recurrence after previous definitive radiation therapy, salvage SBRT may be offered for a durable local control which may lead to a meaningful disease free survival without additional chemotherapy. Further study for SBRT salvage in this setting is being planned.

\section{Acknowledgements}

We would like to thank Drs. Stephen Bader, Christine Cha, Marka Crittenden, David Gannett, Eric Hansen, Jeannie Louie, and Alice Wang-Chesebro for their support.

\section{REFERENCES}

[1] P. Coy and G. M. Kennelly, "The Role of Curative Radiotherapy in the Treatment of Lung Cancer," Cancer, Vol. 45, 1980, pp. 698-702.

doi:10.1002/1097-0142(19800215)45:4<698::AID-CNCR 2820450414>3.0.CO;2-8

[2] P. H. Graham, V. J. Gebski and A. O. Langlands, "Radical Radiotherapy for Early Nonsmall Cell Lung Cancer," International Journal of Radiation Oncology • Biology • Physics, Vol. 31, 1995, pp. 261-266. doi:10.1016/0360-3016(94)E0137-9

[3] D. E. Dosoretz, M. J. Katin, P. H. Blitzer, et al., "Medically Inoperable Lung Carcinoma: The Role of Radiation 
Therapy,” Seminars in Radiation Oncology, Vol. 6, No. 2, 1996, pp. 98-104. doi:10.1016/S1053-4296(96)80006-3

[4] J. Noble, P. M. Ellis, J. A. Mackay and W. K. Evans, "Second-Line or Subsequent Systemic Therapy for Recurrent or Progressive Non-Small Cell Lung Cancer: A Systematic Review and Practice Guideline,” Journal of Thoracic Oncology, Vol. 1, No. 9, 2006, pp. 1042-1058. doi:10.1097/01243894-200611000-00021

[5] K. L. Wu, G. L. Jiang, H. Qian, et al., “Three-Dimensional Conformal Radiotherapy for Locoregionally Recurrent Lung Carcinoma after External Beam Irradiation: A Prospective Phase I-II Clinical Trial,” International Journal of Radiation Oncology • Biology • Physics, Vol. 57, No. 5, 2003, pp. 1345-1350. doi:10.1016/S0360-3016(03)00768-5

[6] T. Tada, H. Fukuda, K. Matsui, et al., "Non-Small-Cell Lung Cancer: Reirradiation for Loco-Regional Relapse Previously Treated with Radiation Therapy,” International Journal of Clinical Oncology, Vol. 10, No. 4, 2005, pp. 247-250. doi:10.1007/s10147-005-0501-1

[7] Y. Okamoto, M. Murakami, E. Yoden, et al., "Reirradiation for Locally Recurrent Lung Cancer Previously Treated with Radiation Therapy,” International Journal of Radiation Oncology • Biology • Physics, Vol. 52, No. 2, 2002, pp. 390-396. doi:10.1016/S0360-3016(01)02644-X

[8] N. Green and R. W. Melbye, "Lung Cancer: Retreatment of Local Recurrence after Definitive Irradiation,” Cancer, Vol. 49, No. 5, 1982, pp. 865-868. doi:10.1002/1097-0142(19820301)49:5<865::AID-CNCR 2820490507>3.0.CO;2-H

[9] J. F. Montebello, B. S. Aron, A. K. Manatunga, J. L. Horvath and F. W. Peyton, "The Reirradiation of Recurrent Bronchogenic Carcinoma with External Beam Irradiation," American Journal of Clinical Oncology, Vol. 16, No. 6, 1993, pp. 482-488. doi:10.1097/00000421-199312000-00004

[10] L. Leksell, "The Stereotaxic Method and Radiosurgery of the Brain," Acta Chirurgica Scandinavica, Vol. 102, No. 4, 1951, pp. 316-319.

[11] J. C. Flickinger, D. Kondziolka and L. D. Lunsford, "Clinical Applications of Stereotactic Radiosurgery," Cancer Treatment and Research, Vol. 93, 1998, pp. 283-297.

[12] D. A. Larson, P. H. Gutin, S. A. Leibel, T. L. Phillips, P. K. Sneed and W. M. Wara, "Stereotaxic Irradiation of Brain Tumors,” Cancer, Vol. 65, No. S3, 1990, pp. 792-799. doi:10.1002/1097-0142(19900201)65:3+<792::AID-CNC R2820651327>3.0.CO;2-P

[13] J. S. Loeffler, D. C. Shrieve, P. Y. Wen, et al., "Radiosurgery for Intracranial Malignancies," Seminars in Radiation Oncology, Vol. 5, No. 3, 1995, pp. 225-234. doi:10.1016/S1053-4296(05)80021-9

[14] D. Kondziolka, A. Patel, L. D. Lunsford, A. Kassam and J. C. Flickinger, "Stereotactic Radiosurgery Plus Whole
Brain Radiotherapy Versus Radiotherapy Alone for Patients with Multiple Brain Metastases," International Journal of Radiation Oncology • Biology • Physics, Vol. 45, No. 2, 1999, pp. 427-434. doi:10.1016/S0360-3016(99)00198-4

[15] D. W. Andrews, C. B. Scott, P. W. Sperduto, et al., "Whole Brain Radiation Therapy with or without Stereotactic Radiosurgery Boost for Patients with One to Three Brain Metastases: Phase III Results of the RTOG 9508 Randomised Tria,” Lancet, Vol. 363, 2004, pp. 16651672. doi:10.1016/S0140-6736(04)16250-8

[16] K. K. Ang, L. J. Peters, R. S. Weber, et al., "Postoperative Radiotherapy for Cutaneous Melanoma of the Head and Neck Region,” International Journal of Radiation Oncology • Biology • Physics, Vol. 30, No. 4, 1994, pp. 795-798.

[17] M. D. Bonnen, M. T. Ballo, J. N. Myers, et al., "Elective Radiotherapy Provides Regional Control for Patients with Cutaneous Melanoma of the Head and Neck," Cancer, Vol. 100, No. 2, 2004, pp. 383-389. doi:10.1002/cncr.11921

[18] S. K. Seung, P. K. Sneed, M. W. McDermott, et al., "Gamma Knife Radiosurgery for Malignant Melanoma Brain Metastases," Cancer Journal from Scientific American, Vol. 4, No. 2, 1998, pp. 103-109.

[19] J. M. Balter and M. L. Kessler, "Imaging and Alignment for Image-Guided Radiation Therapy,” Journal of Clinical Oncology, Vol. 25, No. 8, 2007, pp. 931-937. doi:10.1200/JCO.2006.09.7998

[20] R. D. Timmerman, B. D. Kavanagh, L. C. Cho, L. Papiez and L. Xing, "Stereotactic Body Radiation Therapy in Multiple Organ Sites,” Journal of Clinical Oncology, Vol. 25, 2007, pp. 947-952. doi:10.1200/JCO.2006.09.7469

[21] L. Potters, M. Steinberg, C. Rose, et al., “American Society for Therapeutic Radiology and Oncology and American College of Radiology Practice Guideline for the Performance of Stereotactic Body Radiation Therapy,” International Journal of Radiation Oncology • Biology • Physics, Vol. 60, No. 4, 2004, pp. 1026-1032. doi:10.1016/j.ijrobp.2004.07.701

[22] L. Papiez, R. Timmerman, C. DesRosiers and M. Randall, "Extracranial Stereotactic Radioablation: Physical Principles,” Acta Oncologica, Vol. 42, No. 8, 2003, pp. 882-894. doi:10.1080/02841860310013490

[23] H. Hof, K. K. Herfarth, M. Munter, et al., "Stereotactic Single-Dose Radiotherapy of Stage I Non-Small-Cell Lung Cancer (NSCLC)," International Journal of Radiation Oncology • Biology • Physics, Vol. 56, No. 2, 2003, pp. 335-341. doi:10.1016/S0360-3016(02)04504-2

[24] R. D. Timmerman, L. Papiez, R. McGarry, et al., "Extracranial Stereotactic Radioablation: Results of a Phase I Study in Stage I Non-Small Cell Lung Cancer,” International Journal of Radiation Oncology • Biology • Physics, Vol. 124, No. 5, 2003, pp. S280-S281. doi:10.1016/S0360-3016(03)01131-3 
[25] Y. Nagata, Y. Negoro, T. Aoki, et al., "Clinical Outcomes of 3D Conformal Hypofractionated Single High-Dose Radiotherapy for One or Two Lung Tumors Using a Stereotactic Body Frame," International Journal of Radiation Oncology • Biology • Physics, Vol. 52, No. 4, 2002, pp. 1041-1046.

doi:10.1016/S0360-3016(01)02731-6

[26] M. Uematsu, A. Shioda, K. Tahara, et al., "Focal, High Dose, and Fractionated Modified Stereotactic Radiation Therapy for Lung Carcinoma Patients: A Preliminary Experience,” Cancer, Vol. 82, No. 6, 1998, pp. 10621070.

doi:10.1002/(SICI)1097-0142(19980315)82:6<1062::AID -CNCR8>3.0.CO;2-G

[27] H. Onishi, T. Araki, H. Shirato, et al., "Stereotactic Hypofractionated High-Dose Irradiation for Stage I Nonsmall Cell Lung Carcinoma: Clinical Outcomes in
245 Subjects in a Japanese Multiinstitutional Study," Cancer, Vol. 101, No. 7, 2004, pp. 1623-1631. doi:10.1002/cncr.20539

[28] Q. T. Le, B. W. Loo, A. Ho, et al., "Results of a Phase I Dose-Escalation Study Using Single-Fraction Stereotactic Radiotherapy for Lung Tumors," Journal of Thoracic Oncology, Vol. 1, No. 8, 2006, pp. 802-809. doi:10.1097/01243894-200610000-00008

[29] P. Kelly, P. A. Balter, N. Rebueno, et al., "Stereotactic Body Radiation Therapy for Patients with Lung Cancer Previously Treated with Thoracic Radiation,” International Journal of Radiation Oncology • Biology • Physics, Vol. 78, No. 5, pp. 1387-1393. doi:10.1016/j.ijrobp.2009.09.070 